Letras, Lima, Univ. San Marcos. 63 (91): 19-27, 1992

\title{
De los métodos y áreas de investigación en Historia del Arte Peruano: Propuesta
}

MARTHA BARRIGA TELLOO

Las investigaciones llevadas a cabo en el país, hasta hace comos años, eran realizadas por profesionales de otras áreas (Arqueología, Arquitectura, Derecho, Historia, Sociología, etc.) - por aficionados. Los resultados eran disparejos y poco útiles para ser empleados en una invesitgación científica.

Sin embargo nombres como el del arquitecto Emilio Harth-Terré, el jesuita Rubén Vargas Ugarte, Guillermo Lohmann, el dominico Domingo Angulo,josấoGercia (Beydee Emilio Mendizábal Losack, Jorge Muelle, Jorge Cornejo Bouroncle Jorge Bernales Ballesteros, Pablo Macera, han contribuido con aportes significativos sobre la materia. Sus trabajos están sustentados en documentos extraídos de archivos nacionales y extranjeros. Los estudios sobre Arte Peruano requieren del esfuerzo de los especialistas pues existe un bagaje muy amplio que tomará mucho tiempo delerminar en todas sus implicancias.

En el campo del Arte Precolombino se cuenta con el valioso aporte de los estudios arqueológicos que continuamente se dan a conocer. Las investigaciones realizadas desde el siglo pasado proporcionan actualmente daios científicamenie comprobados. En base a éstos, el historicador de arte elabora su trabajo, complementado con la observación de los objelos existentes, los análisis estilísticos correspondientes y la revisión de la bibliografía apropiada al sentido de su investigación.

Respecto al arie colonial el panorama se presenta más incierto. Aunque es valioso el material publicado hasta hoy sobre la materia, es insuficiente para la elaboración de sistemas 
que permitan la formulación de hipótesis determinantes. Cualquier tema de interés para el estudioso requiere ser complementado por una investigación previa sobre la época, en sus diversos aspectos socio-económicos y culturales. Hay publicaciones al respecto, pero en ellos el sector dedicado al artesanado artístico y al papel de la Iglesia en la formación de la sociedad colonial ha sido medianamente enfrentado. Igualmente se hace indispensable una labor paciente de archivo. Estos no cuentan con caíálogos de consulta, lo que dificulta la búsqueda. Se cñade a ello la pérdida ó el deterioro de importante documentación, lo que muchas veces limita la formulación de conclusiones. La consulta a repositorios extranjeros se convierte en una necesidad insoslayable.

La visita al archivo es indispensable, descle el momento que debe asegurarse al máximo la veracidad de cualquier resultado. Lo reciente de una disciplina como ésta en el Perú hace que ol esfuerzo de los estudiosos en gran parte se centre en la etapa de recopilación de fuentes. Los temas emprendidos se refieren a la Pintura, Escultura, Arquilectura, Problemática de la relación Iglesia-Arte, Crítica, Museología, Catálogos, Arte Popular, Bibliografías y Música. La desaparición, pérdida o deterioro, la inaccesibilidad del documento o del objeto de estudio dilata el análisis. La labor archivística es complementaria, nunca definitiva en el conocimiento del tema. La falia de éste constriñe visiones de conjunto, pero la reconstrucción del objeto a través del documento no Hlega a suplirlo.

Respecto a épocas más recientes, como son el siglo XIX y XX, se presentan mejores piesibilidadeseporate $\$$ se cuenta con fuentes directas de estudio Hay fácil acceso fo los documentos y la existencia de las obras permite conclusiones verificables. El esiado de conservación suele ser bueno y muchas de ellas jamás han sufrido transformaciones naturales o provocadas. Igualmente se apoya en los estudios que aparecen continuamente sobre diversos aspectos sociales e históricos de la época, desde variados puntos de visia. En muchos casos la consulta a testigos presenciales y a los artistas, suscitan el interés que existe por el estudio de esta elapa.

\section{METODO DE ESTUDIO}

Cada investigador adopta el método adecuado a su trabajo o combina tendencias conforme avanza en sus objetivos. Se parte de lineamientos generales, ya que hasta hoy no existe un sistema concluyente que puede aplicarse al estudio de la Historia del Arie, utilizándose mayormente aquellos pertenecientes a la Historia. Dentro de estos, sin embargo, debe buscarse el 
equilibrio que evite considerar la obra de arte exclusivamenLos procedimientos históricos comprobados, son los que deben manejarse. Paralelamente debe considerarse una finalidad, que además de considerar el carácter documental de la obra de arte, tenga en cuenta que representa la concretización de una idea en una forma delerminada, no suceptible de ser sustituída.

El primer enfrentamiento al tema supone la adquisición de conocimientos relacionados al mismo. Para ello el investigador debe emprender la tarea de búsqueda de fuentes, éditas e inédiias: labor heurística. Debe partir previamente de conocimientos básicos sobre el Arie, estableciendo relaciones de semejanza y determinando las distinciones que individualizan la obra de arte, aquellas que caracterizan su época, las que la definen estilísticamente y su significación histórica. La obra de arte es parte de la hisioria y a través de ella es posible reconstruirla haciéndola aparecer en su propia significación.

Estudiar una obra de arte exige una previa labor de reconstrucción. Sólo podemos asegurar la correcta interpretación de ella en cuanto se logre cumplir con este requisito. Para ello podemos observar el objeto y determinar su estado actual. Cerciorarnos de si su apariencia es la misma que concibió el artista. Habrá que distinguir las alteraciones que pudieran haberla modificado.

Un medio eficaz para lograr este objetivo es el estudio de las fuentes documentales, ya señalado. Debe anotarse que estas fuentes, respecto a la reconstrucción de una obra, deben manejarse cuidadosamente y con senlido crítico. Muchos son los factores que ocasionan que una descripción -incluso de fuente directa- no sea fidediging. i Bara cello se recurre,ga la comparación de fuenies y al estudio de las mismas, para aclarar su veracidad. (descripciones apresupudas, "bor encargo, como" parte de un documento coficial cuyo fin inmediato no es es describir la obra, autores interesados a favor o en contra del artista o del mecenas, exceso de imaginación en el autor, etc. son aspectos a considerar).

La aparición de la fotografía brindó un gran aporte al estudio documental. Esta tarea es lenta, difícil y suele ocupar gran parte del tiempo del investigador. A pesar de ello, significa sólo una preparación de la verdadera tarea de la Historia del Arte. La reconstrucción así lograda en algunos casos es aproximada e hipotética; en otros permite abordar el tema desde ángulos no considerados en la premisa inicial. Debe tomarse en cuenta también en esta tarea los principios bajo los que fue creada la obra, la intención y su contexto, de otra manera habrá detalles ininteligibles para su interpretación.

Parte de los méiodos utilizados para la reconstrucción de una obra deben referirse a la certificación de su cutenticidad. Para ello se recurre a sistemas auxiliares, los que actúan sobre la ma- 
teria, como son los Rayos $\mathrm{X}$, Carbono 14, $\mathrm{y}$ otros análisis químicos. Comprobar la autenticidad de una obra hace posible el estudio de las técnicas, su origen, procedencia y el procedimiento utilizado por el artista. La limpieza de un cuadro en ocasiones brinda datos insospechados al investigador. Por otra parte permite aclarar la génesis de la obra, las modificaciones llevadas a cabo por el mismo pintor durante el proceso de factura, o posferiormente por manos extrañas, la participación de discípulos y las posibles suplantaciones fraudulentas de las obras.

El historiacor esiá premunido así de información que le permite abordar, con una sólida base, la interpretación. No debe descuidarse que existe una íntima relación forma-contenido y material en la obra de arte como categorías indivisibles en interacción variable según las épocas.

El estudio y crítica de la fuentes (Erudición), es el próximo paso a seguir, el que generalmente es simultáneo con los anteriores. La Historia del Arte se vale de ellos para aclarar la visión que tiene sobre los objetos de investigación y certificar su cutenticidad. La fuente en sí misma no es la materia de estudio. Los documntos le brindan al historiador de arte, datos adicionales sobre los promotores, los receptores e incuso sobre el autor de la obra, pero no le dan la obra en sí. Esta existe real y verdaderamente, por lo tanto todo estudio es antes que nada de observación. Se da sin embargo el caso de los objetos que llegan a conocimiento del historiador exclusivamente a través de los registros, pues ya no existen. El estudio en estos casos es limitado y nunca determinante.

Las fuentes usadas en la Historia del Arte se dividen en Directas e Indirectas. Gas pHifferas se reflererp" a aquellas que están en conexión estrecha con el objeto, el individuo, la época, etc.

\section{DIRECTAS:}

- Noticias, relaciones, crónicas, anales, cartas, descripciones contemporáneas de testigos presenciales, noticial: material de archivo.

- Obras históricas que traten de la obra, autor o caso de estudio.

- Testimonios personales de los artistas (carias, diarios, orales).

- Faciuras, contratos, protocolos, libros de cuenias, etc.

- Bocetos, estudios y otros. 
INDIRECTAS: Se considera a aquellas que pudieron influir de manera exterior en la obra, pero no están estrechamente ligadas a ella:

- Tratados de talleres, disposiciones generales, reglas, normas, leyes, técnicas, y sistemas difundidos masivamente.

- Los estímulos literarios o de otro tipo que pudieran haber influído en la iconografía de la obra.

- Tradiciones religiosas y culturales en general.

- Condiciones socio-culturales.

El manejo eficaz y riguroso de las fuentes ha constituído la mayor contribución de los hisioriadores de arte al avance del carácter científico de la disciplina.

Toda investigación en este campo debe recurrir a las ciencias auxiliares de la Historia: Paleografía (Doctrina del desarrollo de la escritura caligráfica y del cesciframiento, por ende la crítica, de los documentos); Diplomálica, (estudia las normas características de los documentos, calidad, tipos, etc.) y la Cronología (datación.

Esto constituiría la labor de base de la tarea del investigador en Historia del Arte.

Posteriormenie la segunda etapa consiste en la interpretación de las fuentes ya debidamente comprobadas. El trabajo hermenéutico ocupa una importente pósición en la especialidad. Qué, cómo y para quién se interpreta ha suscitado diversas tendencias y modificaciones. Los medios de interpretación también han variado continuamenter. Esio trajo como consecuencia la incorporación de terminologia perteneciente-a btras ciencias, las que se fueron agregandoJ Qr persaroni celcontomares el vacabulario considerado propio de esta disciplina. A partir de este lenguaje el historiador de arie se convierte en un nexo entre la obra y el receptor. Procura aclarar el sentido de la obra, hacerla evidente a los ojos del receptor en sus múltiples acepciones. Debe considerarse además que la obra de arte emite su propio significado, ajena a las consideraciones del estudioso y de lo que las fuentes hayan contribuído a determinar.

Las líneas de interprelación que adopta el historiador de arte son varias según las tendencias psicológicas, sociológicas, antropológicas que adopte. Aciualmenle se atiende al estudio del arte en base a la historia comparada, que permite una descripción distinta, hasta cierio punto relativa, pero fidedigna.

La comparación de un objeto con otro evidencia, frecuentemenie, aspectos y propiedades no parceptibles por otros sistemas. La tarea es más lenta en cuctito la confrontación abarca hechos y circustoncias no necesariamente artísticos, pero cada logro se afianza firmemente en la secuencia de la investigación. 
De ello depende el procedimiento riguroso al que aspira la Historia del Arte como ciencia.

El método de la investigación en la especialidad puede entonces resumirse en los siguientes puntos:

A. Fijar un tema a investigar.

B. Recopilación de información (busqueda de fuentes y trabajo de campo para localizar las obras).

C. Elaboración, análisis y ordenación de los datos obtenidos. Establecer las áreas de acuerdo a un orden sistemático. Estado de la cuestión.

D. Estudio de la obra "in situ". Descripción, variaciones, trabajos de análisis formal y de reconstrucción.

E. Elaboración y estudio de los puntos preparados confrontados con la obra.

F. Interpretación. Difusión. (1)

La Historiografía del Arte en el Perú estár en sus inicios. Las recién formadas promociones de especialistas en la materia en la U.N.M.S.M. hacen predeeir que arvanzará con mayor continuidad a partir de ahora. Se observa interés creciente en dedicarse al estudio del Arte Peruano. Son conscientes de lo importante que son los estudios rigurosos, científicos, que brinde una sólida base interpretativa al Arte Peruano de todas las épocas.

Es necesario ir superando etapas, ampliar el panorama de conocimientos bibliográficos y documentales dispersos en repositorios religiosos y laicos. Macionales y extrabjeros. La tarea en esta elapa inicial estájen lop ingratal abor des lacalización de fuentes, valorización de datos, en otras palabras depurar las interpretaciones en las que la improvisación prevaleció sobre la exactitud. La seriedad y continuidad con que se emprenda esle trabajo redundará en beneficio del avance de la Historia del Arte en el país y en el mejor conocimiento del arie nacional.

Es en base a este contexto que se inscribe la recilización de la propuesta que presentamos. Inicialmente fue aplicado a estudiantes que ingresaban a la especialidad de Atte en la Escuela Ácadémico Profesional de Arte de la U.N.M.S.M. Suponía introducirlos en un lenguaje que aplicarían constaniemente durante el periodo de estudios. Esta experiencia hizo evidente que el descono cimiento que de él tenían se rastreaba desde la formación escolar. En 1983 tuve oportunidad de ser requerida por la Facultad de Educación de la U.N.M. de San Marcos, para

(1) Para mayor amplitud en el tema véase: BAUER, Herman. Historiografía ciel Arte, Madrid, Ed. Taurus, 1981. 
hacerme cargo de los cursos de Historia del Arte para el Post-Grado de Educación por el Arte, que estaba dirigido a profesores que tenían a su cargo el dictado de los cursos de Arte en los colegios. y que necesitaban ampliar su metodología. Posteriormente recibí similar, encargo para el ciclo de Profesionalización organizado por la misma Facultad de Educación. En esía oportunidad los profesores en ejercicio opiaban por un Bachillerato universitario del que, por proceder de otros centros superiores de enseñanza, carecían. No se dedicaban al dictado de la materia en su mayoría, pero para entonces ya había yo llegado a la conclusión, que cualquier curso era posible complemeniarlo con información "alfabética", de Arte.

Los resultados obtenidos fueron alentadores en cuanto a comprobar la bondad del sistema. Los alumnos-profesores demostraban entusiasmo tanto personal, por el avance que lograban en la comprensión de objetos de Arte que antes les eran lejanos, como porque los alumnos en quienes aplicaban el sistema denotaban una admiración creciente a medida que progresaban en el conocimiento del alfabelo que se les impartía. La sustentación del procedimiento será expuesta más adelante, tal como se explicaba a los profesores asistentes a los cursos, y de acuerdo a las continuas propuestas que llevamos a los encuentros de la Sociedad Peruana de Educadores per el Arle, que contribuímos a formar.

Añadomos a ello lo que la larga Introducción que presentamos cyucia a comprender. La enseñanza del Arte - sea dirigida a niños, jóvenes o adultos-, no puede improvisarse, tal como desgraciadamente incenfiva da política educativa en nuestro país. La responsabilidad del profesor dedicado a ella en inmensa. Las autoridadess eduedeionales poresup parte, ignoran las implicancias de su falta de previsión y de su indiferencia al respecto. La exposición que hemos presentado más arriba, sobre importancia, métodos y objetivos de la Historia del Arte, está orientada a presentarla en su exacta dimensión para salirle al paso a las concepciones que la sitúan en el ámbito de la distracción y el adorno. 
PROPUESTĀ DE UN METODO EN LA PEDAGOGIA DE LA. HISTORIA DEL ARTE EN EL PERU

\section{LA EDUCACION Y EL ARTE*}

Se ha escrito frecuentemente que el Arte debe ser la base de la educación, en la que tendría como finalidad orientar las tendencias positivas del hombre hacia la integración, sincera, justa y libre en la sociedad en que se desarrolla. Los métodos a aplicarse esián circunscritos a la más adecuada manera de familiarizar al individuo con la imagen visual, musical, literaria, etc. de forma de orientar su sensibilidad. Ia educación, en tai sentido, tiene una finalidad práctica, cultivando los modos de expresión en el niño, brindándole la posibilidad de "hacer" antes que, exclusivamente, "contemplar" los objetos artísticos.

Desde su nacimiento el Arte estuvo arientado al hombre, existe en él y por él. Los conocimientos acumulados hasta hoy respecto a este punto, nos permite afirmar la íntima conección entre el Arte y la Sociedad con la que se vincula. En unos periodos más que en otros las sociedades estuvieron identificadas con las expresiones artísticas en sus múltiples manifestaciones. En aquellas etapas en las que el lenguaje visucl era e! único que podía ser comprendido por todos, la población manejaba una serie de conceptos que le permitían comunicarse a través de los signos artísticos. Estos se habían desarrollado en la práctica, por la insistencia que ponían sus autores d propieiadores, en que se difundieran conocimientos cque posibilitatín cau comprensión. Evidentemente, entonces, la imagen era el vehículo de propaganda que solamente podía ser eficaz en la medida en que cumpliera su cometido. El lenguaje debía ser aquel con el que los grupos humanos estuvieran familiarizadios y formaran parte de sus propias vidas.

No escapa al análisis el hecho de que por siglos la misión del Arte en la sociedad fue fundamental para preservar órdenes establecidos. Tampoco puede negarse que es en la expresión artística donde comenzaron a manifestarse los sintomas del desacuerdo, de las nuevas ideas y de los cambios que afectarian a toda sociedad. Un ejemplo muy claro de esa circunstancia es el advenimiento, a fines del siglo XVIII, de la elapa que se ha de. nominado Neoclasicismo. Asumido por las clases dirigentes en sus inicios pasa a ser el portavoz de las idecas liberales de su siglo y posteriormente de posiciones aulocráticas.

* Ponencia Presentada en el I Encuentro de Educación por el Arte. Lima. 13-19 Febrero de 1985. 
En nuestro pais el Arte propiciado por las autoridades virreinales - civiles y religiosas- estaba igualmente cargado de un gran impulso de carácter político. Naturalmente, no es este el único carácter que configuró las características de nuestros trecientos años de etapa virreinal, pero sí es una muestra de las tendencias que arraigaron en la población, una cierta rigurosidad y estatismo de los oue difícilmente podría liberarse.

En innegable, entonces, el impacto que los objetos visuales causan en el hombre. A través de ellos puede inculcársele valores imperecederos desde su más temprana edad. Considerando todo esto debemos poner atención en algunos aspectos que suelen descuidarse cuando se trata de artes específlcas como la $\mathrm{Ar}$ quiteciura, Pintura, Escultura. Aspectos que, sin embargo, cobran toda la aiención de quienes se dedican a la Literatura.

Por ejemplo, al niño se le introduce en el lenguaje oral, pero inmediatamente que está en condiciones, se insiste para que pueda aprender a manejar la lectura. Largas horas pasará aprendiendo las letras, sílabas, palabras. Se le brindaran luego pequeños textos que irán siendo más densos y complicados a medida que madure su "comprensión" del lenguaje, y con ello, él mismo. Si posteriormente demuestra doles literarias, prontamente se le aconsejaran lecturas apropiadas, que lo introduzcan en el amplio mundo de los grandes escritores. Su formación requerirá esta nutriente que le permitirá alcanzar su propio estilo, manifestar su capacidad imaginativa irrestrictamente, y valerse adecuadamente de los medios que el lenquaje, para entonces suficientemente dominado, le permita. Encontraremos muchos escritores de valía que afirmeh habereseguido estos pasos indispensables.

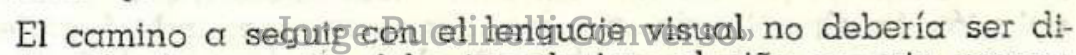
ferente. Desde pequeño debe introducirse al niño en este campo, ofreciéndole progresivamente algunos datos simples que llamen su atención hacia las muestras de Arte Peruano y Universal. El niño se interesa por historias que se pueden deducir del arte figurativo y se entusiasma con las líneas y colores del arte no figurativo, tan cercanas a su propia experiencia. Los monumentos arquitectónicos lo impresionan igualmente por los elementos identificables de su mundo que hallan en ellos. Posieriormente y sin presiones, puede introducírsele en el mundo del museo. Junto con ello se le debe ir brindando elementos del alfabeto visual, que se irán integrando en sílabas, palabras, elementos visuales coherentes. Estaría de esta manera capacitándose para enfrentar las obras concielas, como en el, carso de sus lesturas iniciales y progresivamente más complicadas de la literatura.

Inicialmenie sólo podrá captar lo anecdótico, lo superficial y fácilmente asimilable. Pero, por lo pronto, ya estará enterado de lo que se trata. Pcdrá diferenciar una técnica de otra, y has- 
ta quizá vislumbrar intuitivamente las características de los estilos. Su formación paralela en otras materias lo llevarán inevitablemente a comparaciones, que resultarán más espontáneas que en el caso de su formación literaria, y allí reside la ventaja fundamental. La imagen visual es captada de una sola vez, ésta completa entonces y no requiere más esfuerzo que el de mirar con atención.

El Arte-educador tiene entonces como responsabilidad, la de alfabetizar al estudiante. No podemos exigir a nuestros jóvenes que comprendan un idioma, una lengua que jamás han aprendido. Podremos pasar mucho tiempo insistiendo y, posiblemente, lleguen a deducir por los gestos aquello que se le quiere comunicar. Pero evidentemente, el mensaje llegará incompleto, porque el emisor maneja reglas y un código del que no participa el receptor. No estará tampoco en condiciones de reconocer los valores que se le quieren impartir, ni el vasor del emisor mismo. Ni tampoco será consciente - por haber recibido el mensaje incompleto- si está siendo manipulado en tal o cual sentido. No será "libre" de escoger, de comprender y en última instancia quedará marginado de la información y por ende de emitir una respuesta. En resúmen estará anulado. El artista crea para los demás, se dirige a un público. Mientras este público no esté instruído masivamente, continuaremos sufriendo los resultados del arte de élite, dirigido a unos pocos favorecidos, los que a su vez y por su situación ventajosa, terminarán por imponer sus propias reglas al artista. El concepto de artista creador solitario no es ya concordante con el actual estado de nuestra sociedod que más que nunca requiere de su participadión l ho "soliteria" sino "solidaria". Su manipulación igualmenjer de Purraimdtieranueotrav redundará en efectos de sentido similares en los miembros de la sociedad que lo observan.

Contra lo que pueda pensarse, esta alfabetización e instrucción que se de a los estudiantes no mermará su capacidad creativa. Estar en condiciones de comprender el lenguaje del Arte y aplicar los conceptos que emanen de él, le hará superar una etapa iniciai exclusivamente contemplativa para adoptar otra de observación madura y crítica, plenamente consciente del mensaje. Su capacidad creativa encontrará libre expresión a través de un lenguaje que pueda manejar conscientemente, y de manera adecuada respecto a aquello que trate de comunicar. No insistiremos en tantos casos en que el mal uso del lenguaje traiciona la intención del artista, o le hace creer que es original, cuando en realidad emplea elementos ya utilizados.

En nuestro medio es hoy urgente instruir al estudiante en el lenguaje y la gramática artística. En todos los niveles, no exclusivamente el escolar. El descuido persistente en este aspecto 
ha hecho que se pierda el respelo por las muestras de Arte que nos rodean, y que deben preservarse. Es la única manera de evitar espectáculos deprimentes y desalentadores que enfrentamos a diario, cuando observamos que los estudiantes, de todos los niveles, pasan a formar parte activa, persistente e irresponsable de los agentes depredadores de nuestro patrimonio artístico. Es tarea de la Educación por el Arte, entre otras que le competen, remediar este mal que lejos de detenerse en las etapas primeras de desarrollo, asciende más tarde a niveles de actuación de mayor responsabilidad, en los que esta carencia infantil no ha sido superada. El esfuerzo y dedicación que aplique el maestro en ello consiguirá que, en pocos años, gran parte de los males que aquejan la conservación y el desarrollo del Arte en nuestro país sean dominados.

Un ejemplo que debe movernos a reflexionar es el que ofrecen los niños y jóvenes al ingresar a un templo. No importa la actitud rebelde y altonera que los mismos presenten al exterior, jamás les veremos hacen ningún movimiento que desdiga del lugar al que ingresan. Hablan en voz baja, avanzan despacio procurando no producir el menor ruido, mucho menos comerán, mascarán goma, silbarán o, se gritaran de un lugar a otro Aún y que no sen practicantes reliqiosos ni creyentes, sienten un respeto que trasciende su indocilidad. Maestros y padres logran este resultado casi sin proponérselo. ¿No podremos aplicar un poco de esta experiencia al respeto que nos debe nuestro país a través de su arte? ¿Nos será tan difícil respetarnos a nosotros mismos, que somos incapaces de admirar nuestra propia obra creada por gendudiones? aste indiferencia es responsable de los difíciles mamentespqueirvivimosn heYsoporque el Perú es un país con el que sus habitantes no se sienten identificados, simplemente porque no lo conocen al no haber intentado descifrar su lenguaje.

\section{EDUCACION - ARTE - CREATIVIDAD}

La enseñanza del Arte a nivel escolar se ha orientado a incentivar la creatividad en el estudiante, manejando los medios técnicos apropiados a esle fin.

Creatividad supone inventar, "producir cigo de la nada, establecer, fundar, introducir por primera vez una cosa, hacerla nacer o darle vida en sentido figurado" según especifica el Diccicnario de la Real Academia Española de la Lengua, en conclusión, es darle vida a una obra que surge de la imaginación.

Implica igualmente, una forma de expresión concreta. Esta expresión debe establecerse entre individuos diversos y por lo tanto considera la especificación clara de los conceptos a transmitir. 
Transmitir conceptos entraña el manejo de un lenguaje coherente, manifestado concisa e inteligiblemente.

Un lenguaje usado de esta manera incluye un receptor y un emisor inteligentes en su uso y variaciones posibles.

Dadas estas circunstancias deviene en comunicación, y por lo tanto en formas de entendimiento entre las partes.

El emisor encuentra en ello una forma de expresión, más enriquecedora en cucnto mayor sea el número de signos que maneje, porque le posibilitará la exacta manifestación de su pensamiento.

Se deduce de ello una forma de conocimiento amplio en posibilidades, que a su vez convierte al individuo que lo emplea en un ente participante en su sociedad, con sentido crítico y responsable.

Considerando todo ello, la Educación del Arte debe orientarse a instruir al estudiante en el lenguaje del Arte, que le permita alcanzar estos fines. Tal como se ha desarrollado hasia hoy esta materia a nivel escolar sólo se ha profundizado en el sentido creativo del niño. En los niveles iniviales los resuliados son óptimos a los fines. Es en el nivel inmediatamente siguienie cuando se hace indispensable varian los esquemas, dándole al niño elementos que pueda memejar conscientemente para comunicar su pensamiento y los conceptos. Ello con miras a que comprenda las manifestaciones del Arte de otras épocas y otros medios socio-culturales.

Comprendiendo, el niño aprenderá a respelar, amar y se habrá logrado su fơmighiónt integrale Ëstatfonnación lo impulsará a buscar mejores condiciones de gonyivencio y respeio a los demás, así como la comprensfón de ofras muestras culturales. Con ello se enriquece la creatividad en tanto se le brindan todas las posibilidades de "ser", cabalmente.

La educación por el arte se ha dirigido a estimular en el niño y el joven esta capacialad de perfeccionar a través de los me dios artísticos su instinto creador, no sujelo a imposiciones y en absoluta libertad. Es positivo que se brinde al niño diversos conocimientos relacionados al manejo de los medios o técnicas, para facilitar su uso y con ello lograr que transmita lo que imagina Hasia este punto el método es apropiado a los fines que se propone.

Sin embargo, en el proceso se tiende a olvidar que gran parte de esia enseñanza debe estar dedicada también a conseguir que reconozca en la obra de otro-contemporáneo ó no- los significados de lo expuesto. Se hace indispensable se le instruya en el manejo del lenguaje del Arte. Ello con miras a que igualmente, conforme su estruciura mental sea más elaborada pueda valer. se de signos que traduzcan el mensaje que le interesa difundir 
y a que pueda comprender las obras de arte de una manera consciente y con sentido crítico.

No tenemos que reiterar el valor de la obra de Arte como instrumento ideológico. El estudiante debe estar premunido de códigos que le permitan enfrentarse a ella inteligentemente. Cortsecuentemente a la CREATIVIDAD debemos añadir el concepto de "comprensión", como meta importante a lograr en el desarro. llo iníegral del estudiante escolar.

Esta COMPRENSION constituye un elemento de integración al medio que le rodea. Contribuye a que se sienta partícipe de una realidad que constantemente le rehuye. Sin este entrenamiento en el lenguaje del Ârte el joven se siente discriminado y ajeno a un entorno que debía serle familiar y al que es importante que aprenda a respetar. Esto sólo se logra a través del conocimiento progresivo desde la infancia. Su falta trae además como consecuencia la equivocada opinión de que el Arte está circunscrito a algunoss privilegiados, quienes por razones diversas, como la clase social y la educación, tienen acceso a ella. También se aduce que el arte es patrimonio de unos cuantos que poseen el "genio" suficiente para practicarlo, con erquella manida afirmación que "el artista nace, no se hace". Eeclarece la falsedad de esta opinión el que translademos su aplicación del plano de la Plástica al de la Literatura, como antes se ha señalado. ¿Puede un escritor serlo, si no ha aprendido a escribir, a leer o a hablar en una lengua que le permita expresar ideas y ser comprendido? La literatura supone el mismo proceso respecto al lenguaje gramatical que se utilice con hrabilidad. A mayor destreza mejores posibilidades de lograr la expresibr Gutedrefleje tcarectamente el pensamiento. Igualmente supendréclff gqptơción fropiada de lo que se quiere comunicar.

Con ello llegamos a un punto clave, la COMUNICACION. Mal podemos establecerla con quien está incapacitado para recibirla. El lenguaje del gesto tiene límites evidentes y claros, sobretodo porque puede dar lugar a que se malinterprete y llevarnos a situaciones equívocas, no importa qué tan espontáneo Y creativo lo consideremos. Esta es una limitación on las Artes Plásticas que, quizá, puede superarse en relación a la Danza y la Música, cuya captación es más inmediata y con las que el individuo esiá familiarizado desde pequeño, por diversas circuns tancias.

El Arte-educador debe considerar estos puntos cuando asume la responsabilidad de guiar al estudiante en este aspecto. El niño $\mathrm{y}$ el joven son permeables a dejarse guiar en el conocimiento del lenquaje artístico. De manera ninguna supone sea una coacción a su capcacidad creadora. Si en caso tuviese inicialmente esta presunción, pronto los resultados que obtiene con su aprendizaje le harán cambiar de parecer. 


\section{CONOCIMIENTO:}

El amplio campo de posibilidades que se le abren al estudiante vale el esfuerzo de orientarlo progresivamente durante su formación escolar. Prácticas realizadas por profesores en diversas oportunidades, que me han sido comunicadas, comprueban que el alumno siente que un mundo nuevo, no avisiado y en ocasiones ni siquiera iniuído, aparece ante sus ojos. Desarrolla en ellos un sentido de seguridad y complacencia que muchas veces sorprende en los que tienen pocos cr̃os $y$, presuntamente, son más indiferentes en este aspecto. Al hacerlo partícipe de su entorno el niño descrrolla un vínculo de afecto que no perderá con los años. Así se evitará espectáculos desalentadores que enconiramos a diario cuando jóvenes -en grupo o individualmente- destruyen obras de nuestro patrimonio artístico, o cuando asisten a espectáculos de Teatro, Ballet u otros, en los que su comportamiento refleja claramente su ignorancia. No reprochamos entonces tanto su conducla como la de sus maestros, que han descuidado su formación. Más deprimente aún cuando egresados del colegio, mantienen esta actitud en centros superiores o en puestos públicos a los que inevitablemente gran parte llega, sin haber logrado vencer esta etapa de analfabetismo crítico.

La responsabilidad que cabe al maestro es mucha, si cons:deramos que no es sólo en los profesores de Arte en quienes recae el compromiso. Cualquier materia escolar puede incentivar el interés por el Arte, ninguna le es ajena. Y no debería serlo, desde el momentobque] seannos conscienteslque, con ello, evitamos males que aflijen a la sociedad actual en los que un joven con una educación amplié e integral dificimente incurrirá. Esto porque habrá ampliado su sentido crítico, su capacidad de razonamiento y comprensión de hechos diversos que le permitirán discriminar la respuesta apropiada a su propio bienestar y al derecho de los demás.

Capacitar al alumno en la observación le facultará asumir una posición crítica. Por oira parte la OBSERVACION sólo será efectiva cuando disponga del lenguaje ordenador indispensable.

Por tanto esta formulación se plantea a dos niveles. Aquel en el que se incentiva la capacidad creadora del estudianie para procurar su libre expresividad, que lo conduzca a la amplitud de criterio y de enfrentamiento a su entorno. Por otra parte se interesa en proporcionar un lenguaje que le permita comunicarse con otros a través de su propia creatividad expresada segura y firmemente, sin limitación de medios y que a la vez lo sitúa en condición de comprender las obras de otros, expresadas en signus comunes a muchos, inteligibles y claros. Paralelo a ello se evi- 
tara que esté desarmado en un mundo en el que 'Ila dominación cultural se realiza $a$ través de los medios de representación... en el que los signos reemplazan a las cosas y por su movilidad pueden ser manipulados imponiendo representaciones de la realidad no necesarias a la sociedad a la que se dirige" (Desiderio Blanco. Conferencia sobre Sintaxis de la imagen).

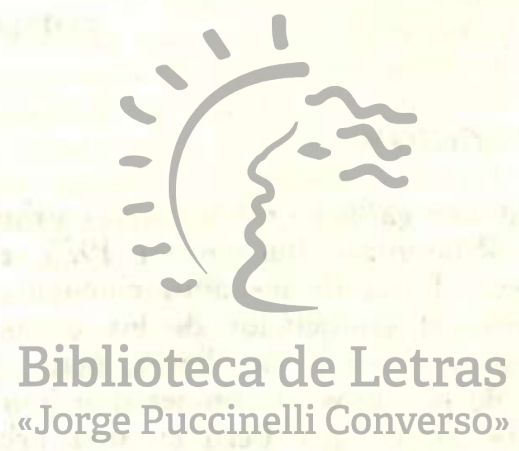

